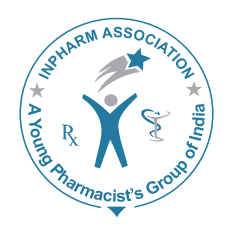

\title{
Pharmacovigilance of Herbal Products in India
}

\author{
Wal P, Wal A, Gupta S, Sharma G, Rai AK \\ Department of Pharmacognosy, Pranveer Singh Institute of Technology, Kanpur, Uttar Pradesh, India \\ Address for correspondence: Prof. Ankita Wal; E-mail: shuklaankita02@gmail.com
}

\begin{abstract}
Herbal formulations being widely accepted therapeutic agents as antidiabetics, antiarthritics, hepatoprotectives, cough remedies, memory enhancers, and adaptogens. The commonest myth regarding herbal medicines is that these medicines are completely safe, and can therefore be safely consumed by the patient on his/her own, without a physician's prescription. This belief has led to large-scale self-medication by people all over the world, often leading to disappointing end-results, side-effects, or unwanted after-effects. There is an increasing awareness at several levels of the need to develop pharmacovigilance practices for herbal medicines. The current model of pharmacovigilance and its associated tools have been developed in relation to synthetic drugs, and applying these methods to monitoring the safety of herbal medicines presents unique challenges in addition to those described for conventional medicines. Several problems relate to the ways in which herbal medicines are named, perceived, sourced, and utilized. This may be because of differences in the use of nonorthodox drugs (e.g., herbal remedies) which may pose special toxicological problems, when used alone or in combination with other drugs. The purpose of pharmacovigilance is to detect, assess, and understand, and to prevent the adverse effects or any other possible drug-related problems, related to herbal, traditional, and complementary medicines.
\end{abstract}

Key words: Adverse reaction, herbal medicines, pharmacovigilance

\section{INTRODUCTION}

Pharmacovigilance is the science and activities relating to the detection, assessment, understanding, and prevention of adverse effects of drugs or any other possible drugrelated problems. Recently, its concerns have been widened to include herbals, traditional and complementary medicines, blood products, and biological..$^{[1]}$ The purpose of pharmacovigilance is to detect, assess, and understand,

\begin{tabular}{|l|l|}
\hline \multicolumn{2}{|c|}{ Access this article online } \\
\hline Quick Response Code: & \\
\hline & Website: \\
& www.jyoungpharm.in \\
& \\
\hline
\end{tabular}

and to prevent the adverse effects or any other possible drug-related problems, which is not only confined to chemical drugs, but extended to herbal, traditional, and complementary medicines, biologicals, vaccines, blood products, and medical devices. The history of the use of herbs as medication is as old as history itself. Some authors state that the first recorded use of herbs for medical treatment began over 4000 years ago. ${ }^{[2]}$ The origin of this type of medical treatment began in China and India. Traditional Chinese medicine centers on interactions between the body and the environment. A mixture of treatments, including herbs, acupuncture, and massage, is then prescribed. Traditional Indian medicine has dated back to $3000 \mathrm{BC}$. One form of traditional Indian medicine is called Ayurvedic. An example of the types of herbal products can be seen in Table 1. In the United 
Wal, et al:: Pharmacovigilance of herbal products

Table 1: Herbal products from different cultures ${ }^{[8]}$

\begin{tabular}{lll}
\hline Type of herbal medication & Natural sources & Origins \\
\hline Ayurvedic & $\mathrm{P}, \mathrm{A}, \mathrm{M}$ & India \\
Chinese & $\mathrm{P}, \mathrm{A}, \mathrm{M}$ & China \\
Indusynunic & $\mathrm{P}, \mathrm{A}, \mathrm{M}$ & Pakistan \\
Islamic & $\mathrm{P}, \mathrm{A}, \mathrm{M}$ & Middle East \\
Aromatherapy & $\mathrm{P}$ & European \\
Herbalism & $\mathrm{P}$ & European \\
Homeopathy & $\mathrm{P}$ & European \\
Botanicals & $\mathrm{P}$ & European \\
\hline
\end{tabular}

P: Medicinal plants; M: Minerals; A: Animal sources

States, herbal therapy began more recently, along with the founding of the country. A combination of European, Chinese, Ayurvedic, and other unconventional treatments influenced the use of herbs to the present day. In almost all the traditional systems of medicine, the medicinal plants play a major role and constitute their backbone. Adverse events may also arise from the misuse of the wrong species of medicinal plants, incorrect dosing, errors in the use of herbal medicines by healthcare providers and consumers, interactions with other medicines, and use of products contaminated with potentially hazardous substances, such as toxic metals, pathogenic microorganisms, and agrochemical residues.

The following examples demonstrate the range of problems encountered with the use of herbal medicines and products. ${ }^{[1]}$

- Some herbal products were found to contain 0.1 to $0.3 \mathrm{mg}$ of betamethasone per capsule after some patients developed corticosteroid-like side effects.

- Owing to misidentification of the medicinal plant species, plant materials containing aristolochic acid were used for manufacturing herbal products, which caused severe kidney failure in patients in several countries.

- Reports have been received by drug safety monitoring agencies of prolonged prothrombin times, increased coagulation time, subcutaneous hematomas, and intracranial hemorrhage associated with the use of Ginkgo biloba.

- One of the most well-known traditionally used herbal medicines caused severe, sometimes fatal cases of interstitial pneumonia, when used in conjunction with interferon.

List of the unapproved Ayurvedic medicinal products found on the Canadian market thus far, which have been analyzed by Health Canada and found to contain high levels of lead, mercury, and arsenic, are as follows:

- Karela tablets, produced by Shriji Herbal Products, India

- Karela capsules, produced by Himalaya Drug, India

- Karela capsules, produced by Charantia, UK (specifically batch \#12011)

- Maha Sudarshan Churna powder, produced by Zandu Pharmaceuticals, Mumbai, India

- Maha Sudarshan Churna powder, D and K Pharmacy, Bhavnagar, India

- Maha Sudarshan Churna powder, produced by Chhatrisha, Lalpur, India

- Maha Sudarshan Churna powder, produced by Dabur India, New Delhi, India

- Safi liquid, produced by Hamdard-WAKF-Pakistan

- Safi liquid, produced by Hamdard-WAKF-India

- Yograj Guggul tablets, produced by Zandu Pharmaceuticals, Mumbai, India

- Sudarshan tablets, produced by Zandu Pharmaceuticals, Mumbai, India

- Shilajit capsules, produced by Dabur India, New Delhi, India

Need of pharmacovigilance in herbals

In order to provide consistency in the naming of herbs in adverse reaction (AR) reports, the WHO Collaborating Centre for International Drug Monitoring has recommended the use of proper scientific binomial names for herbs used in medicine, including the use of such names (where this information is available) in the coding of AR reports. ${ }^{[3]}$ This would ensure comparability between reports from various international pharmacovigilance databases. It is equally important for the authors of published AR case reports to identify the specific product(s) involved, including label and manufacturer information, specific ingredients, and dose employed. Published case reports would also benefit from analysis of the suspect product used, for contamination and adulteration, or species identification, where possible.

\section{Herbals concept of adverse effect}

An AR is defined as a noxious and unintended response to a marketed health product, which occurs at doses normally used or tested for the diagnosis, treatment, or prevention of a disease or the modification of an organic function. ${ }^{[4]}$ It is undeniable that plants have an important role in the development of modern medicines. More than 60 to $70 \%$ of modern medicines in the world market are directly or indirectly derived from plant products. Highprofile issues such as ARs associated with Ephedra and Aristolochia have shown that HMPs can produce toxicity in human beings. The most common adverse effects reported are hepatic and renal problems. However, it is difficult to identify the causative agent associated with the ARs encountered because traditional herbal preparations often contain multiple ingredients. The WHO database has 
over sixteen thousand suspected herbal case reports. Due to the lack of clinical trials for most HMPs, postmarket pharmacovigilance is a critical source of safety information; however, the assessment of ARs associated with HMPs offers unique challenges in the quantity and quality of available information. ${ }^{[5,6]}$

\section{Adverse reaction reports: Quality}

The quality of ARs depends in part on educating potential reporters of what types of data are valuable for assessment. Such educational efforts can take the form of online educational modules, such as those directed at naturopathic doctors in Canada. ${ }^{[7]}$ In order to provide consistency in the naming of herbs in AR reports, the WHO Collaborating Centre for International Drug Monitoring has recommended the use of proper scientific binomial names for herbs used in medicine, including the use of such names (where this information is available) in the coding of AR reports. ${ }^{[8]}$ This would ensure comparability between reports from various international pharmacovigilance databases. It is equally important for the authors of published AR case reports to identify the specific product(s) involved, including label and manufacturer information, specific ingredients, and dose employed. Published case reports would also benefit from analysis of the suspect product used, for contamination and adulteration, or species identification, where possible. A lack of, or incorrect, herbal identification has been noted as a potential source of confusion in published case reports of HMP toxicity. ${ }^{[9]}$

\section{RECOMMENDATIONS}

There are several ways in which we can move forward in attempting to provoke pharmacovigilance in herbals.

1. Introduce pharmacovigilance concepts into the curriculum of herbals at the undergraduate and postgraduate level.

2. Make reporting of adverse reactions to regulatory mandatory for herbal formulations.

3. Human resource development is a key feature for the success of this enterprise. It will be necessary to train herbal experts in the science of pharmacovigilance and include them not only in reporting but also in assessment of the adverse reactions.
4. Healthcare professionals should remain vigilant for potential interactions between herbals and prescription medications, especially when it involves medications with narrow therapeutic indices. Due to the wide use and easy availability of herbal medicines, herbal toxicity has become an issue of concern. The safety and quality of herbal medicine should be ensured through greater research, pharmacovigilance, greater regulatory control, and better communication between patients and health professionals. The recommended approach is to include herbal medicines in existing national pharmacovigilance systems or, where such systems have not yet been developed, to establish comprehensive national pharmacovigilance systems which incorporate coverage of herbal medicines. Pharmacovigilance in herbal medicine in India is perhaps an unthought of concept as yet; we do not need "Herbal thalidomide" to wake the pharmacovigilance community to the need of the hour.

\section{REFERENCES}

1. WHO guidelines on safety monitoring of herbal medicines in pharmacovigilance systems. World Health Organization: Geneva;2004. p.19.

2. Williamson E. Drug interactions between herbal and prescription medicines. Drug Saf 2003;26:1075-92.

3. Jordan SA, Cunningham DG, Marles RJ. Assessment of herbal medicinal products: Challenges, and opportunities to increase the knowledge base for safety sassessment. Toxicol Appl Pharmacol 2010;243:198-216.

4. Health Canada, 2009a. Release of the guidance document for industry reporting adverse reactions to marketed health products. July 09, 2009. Available from: http://www.hc-sc.gc.ca/dhp-mps/pubs/medeff/_ guide/2009-guidance-directrice_reporting-notification/index-eng.php. [last accessed on 2009 Sep 28].

5. Farah MH, Edwards R, Lindquist M, Leon C, Shaw D. International monitoring of adverse health effects associated with herbal medicines. Pharmacoepidemiol Drug Saf 2000;9:105-12.

6. Gardiner P, Sarma DN, Dog TL, Barrett ML, Chavez ML, Ko R, et al. The state of dietary supplement adverse event reporting in the United States. Pharmacoepidemiol Drug Saf 2008;17:962-70.

7. Health Canada, 2006. Reporting adverse reactions for naturopathic doctors. Available from:http://www.hc-sc.gc.ca/dhp-mps/medeff/centre-learnappren/nd-dn_ar-ei_module-eng.php. [last accessed on 2009 Sep 23].

8. Farah MH, Olsson S, Bate J, Lindquist M, Edwards R, Simmonds MS, et al. Botanical nomenclature in pharmacovigilance and a recommendation for standardisation. Drug Saf 2006;29:1023-9.

9. But PP, Atherton DJ, Rustin MH, Brostoff J. Need for correct identification of herbs in herbal poisoning. Lancet 1993;341:637-8.

How to cite this article: Wal P, Wal A, Gupta S, Sharma G, Rai AK. Pharmacovigilance of herbal products in India. J Young Pharmacists 2011;3:256-8.

Source of Support: Nil, Conflict of Interest: None declared. 